\title{
Processo de formação e expansão urbana do Distrito Federal*
}

\section{The formation and urban expansion of the Federal District}

Daniela Vieira Oliveira' Regina de Souza Maniçoba²

\section{Resumo}

Embora tardio, o processo de urbanização no Brasil, uma vez iniciado, atingiu números exorbitantes num período muito pequeno de tempo. O mesmo ocorreu com Brasília que, prevista para abrigar de 500 a 700 mil habitantes, teve sua população aumentada e seu território expandido, chegando a atingir no Censo de 2010, um total de 2.570.160 habitantes (IBGE, 2014). Nesse sentido, o presente artigo tem como objetivo analisar como se deu o processo de formação e expansão urbana do território do Distrito Federal (DF) buscando ressaltar os fatores que motivaram este crescimento e as perspectivas futuras para a Capital.

Palavras-chave: Geografia. Urbanização. Distrito Federal (Brasil). Crescimento populacional.

\begin{abstract}
Although late, the urbanization process in Brazil, once started, reached exorbitant numbers in a very short period of time. The same happened with Brasília that planned to house 500-700 thousand inhabitants, had increased its population and its territory expanded, reaching the 2010 Census, a total of 2,570,160 inhabitants (IBGE, 2014). In this sense, this article aims to analyze how was the process of formation and urban expansion of the territory of the Federal District (DF) seeking to highlight the factors that led this growth and future prospects for the Capital.
\end{abstract}

Keywords: Geography. Urbanization. Federal District (Brazil). Population growth. 


\section{Introdução}

Diferente do que ocorreu nos países desenvolvidos, o desenvolvimento do processo de urbanização no Brasil foi tardio, tendo se estabelecido somente na segunda metade do século XX. Foi apenas após a década de 1960 que a parcela da população urbana superou a rural. Mas, uma vez estabelecido, o processo de urbanização cresceu rapidamente.

No Brasil, a velocidade do processo de urbanização foi muito superior à dos países capitalistas mais avançados. "Apenas na segunda metade do século XX, a população urbana passou de 19 milhões para 138 milhões, multiplicando-se 7,3 vezes, com uma taxa média anual de crescimento de 4,1\%" (BRITO; SOUZA, 2005).

No DF ocorreu o mesmo fenômeno, em poucas décadas a população urbana cresceu a números exorbitantes. Fato este, que contribuiu para que a cidade, mesmo nascida após um planejamento baseado nos preceitos do Urbanismo Moderno, apresentasse os principais problemas das demais Metrópoles brasileiras.

Nesse sentido, o presente trabalho pretende analisar o processo de formação e expansão urbana do $\mathrm{DF}$ com o intuito de identifica os fatores que motivaram este crescimento e as perspectivas futuras para a Capital.

Para isso, tratou-se inicialmente sobre o processo de urbanização no Brasil e como se deu a expansão urbana durante várias décadas, enfatizando que o crescimento populacional desordenado possibilitou que este se tornasse urbano rapidamente, mas sem qualidade e planejamento adequados. Depois, discutiu-se a mudança da capital para o interior que ensejou o crescimento da urbanização do Centro-Oeste. E, por fim, passou-se para a análise de como se processou a organização do espaço do DF antes mesmo da inauguração da cidade até os dias atuais.

\section{A urbanização no mundo e no Brasil}

O processo de urbanização mundial foi grandemente impulsionado pela Revolução Industrial (século XVIII) iniciada na Inglaterra por volta de 1780 . Conforme cita Mumford (1961, p.155),

[...] em 1800, tinha Inglaterra uma população de pouco mais de nove milhões de habitantes, a Alemanha tinha por volta de vinte e quatro milhões, a França ao redor de vinte e sete milhões, e os Estados Unidos não muito mais de cinco milhões. Por volta de [1830], as suas populações tinham aumentado, em números redondos, respectivamente para quarenta e cinco milhões, sessenta milhões, quarenta e dois milhões e cento e vinte e três milhões. [...]. A urbanização cresceu quase que em proporção direta à industrialização: na Inglaterra e na Nova Inglaterra, chegou a um ponto em que quase oitenta por cento da população total estava morando em centros de mais de vinte e cinco mil habitantes.

Graças ao incentivo dado pela industrialização, grande contingente populacional foi se deslocando para as cidades, que se multiplicaram e tiveram o número de habitantes aumentado em grande escala. Conforme Mumford (1961), tão logo a concentração de fábricas estimulou o crescimento de cidades, o aumento da população destas tornou-se espantoso.

Tendo a segunda metade do século XX como marco, a urbanização mundial avançou a passos largos. Nesse período, o crescimento da população urbana mundial atingiu números excepcionais. Conforme dados do IPEA/ IBGE/UNICAMP/IE/NESUR (2001, p. 320), enquanto o crescimento da população urbana foi de $240 \%$ entre 1900 e 1950 , o da população total foi de $49 \%$. No período posterior, entre 1950 e 1990, o aumento se manteve, havendo o número de pessoas vivendo nas cidades passado de 733 milhões para mais de 2 bilhões.

Até a segunda metade do século XX, o maior crescimento da população urbana esteve concentrado nos países desenvolvidos. A partir desse período, porém, ele se desloca para os países em desenvolvimento, que ultrapassam os industrializados e passam a concentrar a maior parte da população urbana mundial. De acordo com relatórios do IPEA/IBGE/UNICAMP/IE/NESUR (2001, p. 320),

a segunda metade do século XX marcou a ruptura radical na história plurissecular da urbanização mundial. Podemos falar de uma inflação urbana que alterou profundamente a distribuição da população do planeta. A maioria, cerca de $60 \%$ do total, vive em cidades de países em desenvolvimento.

Há que se considerar, no entanto, que o processo de urbanização se deu de forma diferenciada nos países desenvolvidos e nos em desenvolvimento. Conforme afirma Castells (1983, p. 79), "a urbanização em curso nas regiões 'subdesenvolvidas' não é uma réplica do processo que atravessam os países industrializados. No mesmo estágio de população urbana alcançado hoje em dia pelos países 'subdesenvolvidos', o nível de industrialização dos países 'desenvolvidos' era bem mais alto".

No caso específico da urbanização brasileira, mes- 
mo que tardia e não tão expressiva quanto a ocorrida nos países desenvolvidos, também houve a intensificação da industrialização (assim como a modernização do campo) como fator que contribuiu para seu aumento.

Milton Santos inicia sua obra Urbanização Brasileira descrevendo a urbanização pretérita do país. Conforme ressalta ele, "durante séculos o Brasil como um todo é um país agrário [...]" (SANTOS, 2005, p. 19). Para justificar tal afirmação cita Oliveira Vianna, para o qual,

[...] o urbanismo é condição moderníssima da nossa evolução social. Toda a nossa história é a história de um povo agrícola, é a história de uma sociedade de lavradores e pastores. É no campo que se forma a nossa raça e se elaboram as forças íntimas de nossa civilização. O dinamismo da nossa história, no período colonial, vem do campo. Do campo, as bases em que se assenta a estabilidade admirável da nossa sociedade no período imperial (VIANNA, 1956, apud SANTOS, 2005, p. 19).

O período de 1500 e 1720, como enfatiza Santos (2005), corresponde a um período denominado por Nestor Goulart Reis de "primórdios da urbanização". Nele, várias vilas e cidades foram sendo criadas formando o início da rede urbana brasileira. Contudo, conforme enfatiza esse autor, é somente a partir do século XVIII que a urbanização se desenvolve ${ }^{3}$, vindo a atingir a maturidade apenas no século XIX.

Santos (2005) ressalta, no entanto, que o processo de criação urbana ocorrido no período colonial foi muito mais de geração de cidades do que propriamente um processo de urbanização, tendo em vista as relações entre os lugares serem fracas, inconstantes, num país de grande extensão como é o Brasil. Mas, apesar disso, "a expansão da agricultura comercial e a exploração mineral foram a base de um povoamento e uma criação de riquezas, redundando na ampliação da vida de relações e no surgimento de cidades no litoral e no interior" (SANTOS, 2005, p. 22).

A quantidade de cidades e o número de pessoas vivendo nelas foi crescendo, mas o índice de urbanização manteve-se pouco alterado entre o fim do período colonial até o final do século XIX, só vindo a aumentar realmente entre 1920 e 1940, quando "a população con-

3 Esse desenvolvimento da urbanização foi caracterizado pela consolidação das casas nas cidades como local principal de residência da população, em substituição a casa no campo onde até então a população mantinha-se a maior parte do tempo. centrada em cidades passa de 4.552 milhões de pessoas em 1920 para 6.208.699 em 1940" (SANTOS, 2005, p. 25).

Depois dos anos 1940-1950, os nexos econômicos ganham relevo, sendo as dinâmicas urbanas impostas à totalidade do território. A partir da Segunda Guerra, as capitais passam a ter um crescimento sustentado e a situação do país, que durante séculos foi um grande arquipélago formado por subespaços que tinham escassa relação entre si, foi relativamente modificada "[...] quando, a partir da produção de café, o estado de São Paulo se torna o pólo dinâmico de vasta área que abrange os estados mais ao sul e vai incluir, ainda que de modo incompleto, o Rio de Janeiro e Minas Gerais" (SANTOS, 2005, p. 29).

É com base nessa nova dinâmica que, como afirma esse autor, o processo de industrialização se desenvolve e São Paulo, que já se destacava das demais regiões, passa a exercer cada vez mais um lugar de primazia e de polarização.

Esse primeiro momento durará até década de 1930, quando novas condições políticas e organizacionais permitem que a industrialização conheça, de um lado, uma nova impulsão, vinda do poder público e, de outro lado, comece a permitir que o mercado interno ganhe um papel, que se mostrará crescente, na elaboração, para o país, de uma nova lógica econômica e territorial [que irá prevalecer a partir dos anos 1940-1950] (SANTOS, 2005, p. 30).

Santos (2005) enfatiza que o forte movimento de urbanização verificado a partir do fim da Segunda Guerra Mundial é contemporâneo de forte crescimento demográfico, resultado de uma taxa de natalidade elevada e de uma queda nas taxas de mortalidade, possibilitadas pelos progressos sanitários e melhoria relativa nos padrões de vida.

Nesse momento posterior ao final da Segunda Guerra, no quadro econômico, o Brasil havia acumulado grande saldo na balança comercial graças à venda de matérias-primas estratégicas aos Aliados, o que pemitiu a acumulação de divisas para o país. Além disso, conforme citam Barbeiro; Cantele e Schneeberger (2004, p. 444), “a indústria nacional passara a aumentar sua produção para o mercado interno, uma vez que havia dificuldade de importações". No entanto, com a retomada das importações após o fim da guerra, as reservas de moeda estrangeira foram se esgotando rapidamente e o déficit provocado pelas importações agravou o desequilíbrio da balança comercial, uma das soluções adotadas pelo governo então foi facilitar a entrada de capitais estrangeiros no país.

Este foi o quadro instalado durante o governo $\mathrm{Du}$ - 
tra (1946-1951). Após este, Getúlio Vargas volta ao poder e, graças à sua política nacionalista e intervencionista, passa a expandir os setores da indústria de base, como a siderurgia, a petroquímica, a energia e os transportes. São criados neste período instituições importantes, como o Banco Nacional de Desenvolvimento Econômico (BNDE) e a Petróleo Brasileiro S/A (Petrobras). Após 1953, a situação política do país se complica: o governo passa a ser duramente criticado $^{4}$, a inflação que desde 1947 vinha crescendo atinge números altos, e o custo de vida aumenta. Todo esse período de instabilidade se agrava e acaba culminando com a morte de Getúlio em 1954. O governo posterior, de Juscelino Kubitschek - JK (1956-1961), vem inaugurar uma nova era no país, de desenvolvimento nos setores de energia, transporte e na indústria de base.

Prosseguindo na discussão sobre o processo de urbanização, mesmo que guardadas as devidas diferenças, pode-se afirmar que a aceleração dessa no Brasil também esteve ligada ao aumento da industrialização. De acordo com dados do IPEA/IBGE/UNICAMP/IE/NESUR (2001, p. 346), foi durante o período compreendido entre 1956-60 a 1975-79, denominado "fase da industrialização pesada", que se iniciou um processo de constituição da rede urbana integrada em âmbito nacional.

A fase da industrialização pesada no país foi proporcionada pelos recursos destinados ao setor de energia e transporte previstos no Plano de Metas do Governo de JK e pelo capital estrangeiro ${ }^{6}$. Graças a esses recursos, a partir da década de 1950, há grande crescimento na indústria de bens de produção, que se refletiu principalmente nos setores siderúrgico e metalúrgico (automóveis), químico e da construção naval.

A partir da década de 1960, com o impulso dado pela intensificação da industrialização, começa a ocorrer uma inversão na quantidade de pessoas residentes na área urbana e rural. Conforme dados dos censos demográficos do IBGE, em 1960 a proporção da população urbana (de 45,1 ) se aproxima da rural (que era de 54,9) e, na década

4 As críticas vêm de todos os lados, da oposição, da população, dos setores empresariais nacionais, associados ao capital estrangeiro.

5 É denominada de pesada, a indústria que consome grandes quantidades de matéria-prima e de energia, como a siderurgia e a mertalugia. seguinte, os números da população urbana saltam para 56,0 , ultrapassando a rural, que ficou em 44,0 (Tabela 1). Na década de 1970 o Brasil já era predominantemente urbano

Tabela 1 - Percentual da população nos censos demográficos por situação dos domicílios 1950 - 2000

\begin{tabular}{|c|c|c|c|c|c|c|c|}
\hline \multirow{2}{*}{$\begin{array}{l}\text { Brasile } \\
\text { Região } \\
\text { Geográfica }\end{array}$} & \multirow{2}{*}{$\begin{array}{c}\text { Situação } \\
\text { do domicílio }\end{array}$} & \multicolumn{6}{|c|}{ Ano } \\
\hline & & 1950 & 1960 & 1970 & 1980 & 1991 & 2000 \\
\hline \multirow{2}{*}{ Brasil } & Urbana & 36,2 & 45,1 & 56 & 67,7 & 75,5 & 81,2 \\
\hline & Rural & 63,8 & 54,9 & 44 & 32,3 & 24,5 & 18,8 \\
\hline \multirow[t]{2}{*}{ Norte } & Urbana & 29,6 & 35,5 & 42,6 & 50,2 & 57,8 & 69,8 \\
\hline & Rural & 70,4 & 64,5 & 57,4 & 49,8 & 42,2 & 30,2 \\
\hline \multirow{3}{*}{ Nordeste } & Urbana & 26,4 & 34,2 & 41,8 & 50,7 & 60,6 & 69 \\
\hline & & & & & & & \\
\hline & Rural & 73,6 & 65,8 & 58,2 & 49,3 & 39,4 & 31 \\
\hline \multirow{3}{*}{ Sudeste } & Urbana & 47,5 & 57,4 & 72,8 & 82,8 & 88 & 90,5 \\
\hline & & & & & & & \\
\hline & Rural & 52,5 & 42,6 & 27,2 & 17,2 & 12 & 9,5 \\
\hline \multirow{3}{*}{ Sul } & Urbana & 29,5 & 37,6 & 44,6 & 62,7 & 74,1 & 80,9 \\
\hline & & & & & & & \\
\hline & Rural & 70,5 & 62,4 & 55,4 & 37,3 & 25,9 & 19,1 \\
\hline \multirow{2}{*}{ Centro-0este } & Urbana & 25,9 & 37,2 & 50,9 & 70,7 & 81,3 & 86,7 \\
\hline & Bural & 741 & 628 & 491 & 293 & 187 & 133 \\
\hline
\end{tabular}

Fonte: Censo Demográfico - IBGE (2000).

Extraído do Banco de Dados Agregados - Sidra7.

Após este período, caracterizado pelo grande adensamento urbano do território brasileiro, tem início o crescimento das grandes cidades, em todas as regiões do país que vão caracterizar o processo de metropolização que vai se consolidar a partir da década de 1970 .

No início da década de 90, as áreas urbanas ultrapassaram o limite dos 100 milhões de indivíduos. A urbanização no Brasil apresentou um ritmo extremamente dinâmico, devido, a dois processos articulados: à concentração populacional nas metrópoles - estas, em 1996, respondiam por cerca de $42 \%$ da população urbana brasileira; à expansão e ao adensamento da estrutura urbana, tanto em áreas de povoamento consolidado, como também na fronteira de recursos (Figura 1).

7 O Banco de Dados Agregados Sidra encontra-se no site do IBGE, Disponível em: <http://www.ibge.gov.br>. 
Figura 1 - Brasil - Crescimento da população urbana (1991 - 1996)

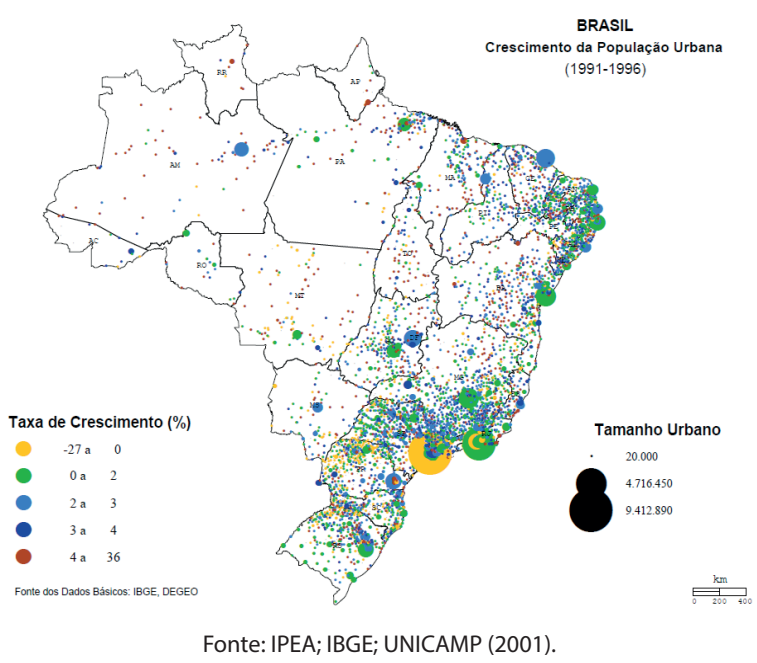

A indústria teve papel fundamental para alavancar o crescimento das metrópoles e das aglomerações urbanas fazendo com que as duas maiores metrópoles da época, SP e RJ, concentrassem, em 1980, a maior porcentagem da população ocupada neste setor e também a maior parte da população do país.

$\mathrm{O}$ crescimento urbano no período mais recente porém, mostra uma perda de velocidade do incremento das grandes metrópoles de São Paulo e Rio de Janeiro e a crescente importância de novas áreas metropolitanas, como as cidades de Fortaleza e de Salvador, e de centros regionais, como Manaus, Campo Grande ou Natal.

Com isso, outras áreas passam a ter destaque com crescente desenvolvimento urbano, como é o caso da Região Centro-Oeste, com a formação de um importante complexo territorial entre Brasília (DF), Anápolis (GO) e Goiânia (GO).

Este salto na urbanização do Centro-Oeste, no entanto, teve impulso ainda em meados da década de 1950, com a transferência da Capital para o Planalto Central.

\section{Mudança da Capital para o interior}

A primeira representação cartográfica de Goiás (Figura 2), local onde se localizaria a Nova Capital, foi feita entre os anos de 1749 e 1751 pelo cartógrafo italiano Francisco Tosi Colombina que estava a serviço do primeiro governador de Goiás, o Conde dos Arcos. Foi ele que desenhou pela primeira vez as bacias fluviais que, da região central do Brasil, banham em todas as direções o território brasileiro.
Figura 2 - Mapa dos confins do Brasil com as terras da Coroa da Espanha na América Meridional, 1749

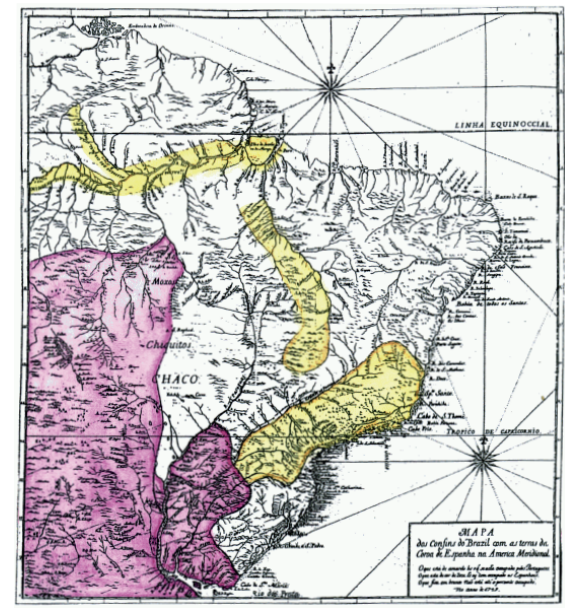

Fonte: UFRJ/IGEO/DEGEO (2003)

Em 1751, fica pronto o primeiro mapa viário do Brasil, que se tornou base para as negociações luso-espanholas que resultaram no Tratado de Madri. Esta carta geográfica realçou o valor estratégico do Planalto Central. Mapa geofísico, fluvial e viário, o Mapa da Capitanhia de Goyás, definia os limites entre Mato Grosso, Goiás, Pará, Maranhão, Pernambuco e as capitanias do sul e retratava o epicentro das nascentes dos maiores sistemas hidrográficos brasileiros, trazendo pela primeira vez informações e rotas, tanto terrestres como fluviais, que ligam o Centro-Oeste ao sul do Brasil.

As primeiras ideias de se criar uma capital no interior do território surgiram no Séc. XVII. Tiradentes sugere que a nova sede do governo fosse estabelecida em São João Del Rei. Já José Bonifácio de Andrade, o Patriarca da Independência, a partir de 1823, defende a criação de uma nova capital já propondo o nome de "Brasília": Brasil em Latim.

Em 1839 a 1877, Francisco Adolfo de Varnhagen, diplomata, defende a ideia de mudar a capital para o Planalto Central. Em 1877, após viagem de São Paulo a Formosa em "lombo de burro", publica trabalho em defesa da interiorização da capital denominado: "A questão da capital: marítima ou no interior?"

Em resposta a todo este movimento de mudança da Nova Capital para o centro do País, a Primeira Constituição Brasileira, de 24 de fevereiro de 1891, trás em seu artigo 3: "fica pertencente à União, no Planalto Central da República, uma zona de 14.400 km, que será oportunamente demarcada, para nela estabelecer-se a futura Capital Federal (BRASIL, 1891)”.

Em 1892, é realizada pela Comissão Exploradora do Planalto Central do Brasil, chefiada pelo astrônomo 
belga Luiz Cruls, a $1^{\text {a }}$ Missão Cruls (Figura 3). Durante esta foram registrados importantes acidentes geográficos como as águas termais de Caldas Novas, o Salto do Itiquira, em Formosa e as nascentes de Águas Emendadas, em Planaltina (berço das bacias hidrográficas do São Francisco, Platina e Amazônica, como já mostrado pelos mapas de 1751 que indicavam a riqueza estratégica do interior do país).

Figura 3 - Membros da Comissão Cruls, 1892

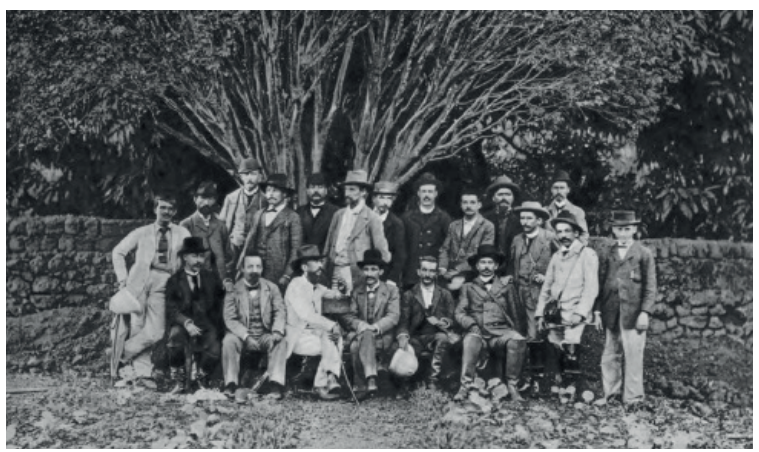

Fonte: El-Dahdah (2010)

A Comissão Exploradora realizou estudos científicos, mapeando clima, topografia, geologia, flora, fauna, cursos d'água, o modo de vida dos habitantes, os aspectos urbanos das cidades encontradas no caminho e os recursos materiais da região do Planalto Central e seus resultados foram apresentados no Relatório Cruls publicado em 7 de maio de 1894.

Este Relatório, por sua riqueza de detalhes, é considerado o mais completo estudo sobre o Planalto Central brasileiro, tornando-se o primeiro Relatório de Impacto Ambiental (RIMA) de nossa história.

A partir desta missão foi desenhada, pela primeira vez, em 1893, no mapa do Brasil, a área conhecida como “Quadrilátero Cruls”, com a expressão "Futuro Distrito Federal” (Figura 4) no Planalto de Goiás.

Figura 4 - Mapa do Brasil de 1893, já com o "Retângulo Cruls" indicando o futuro DF

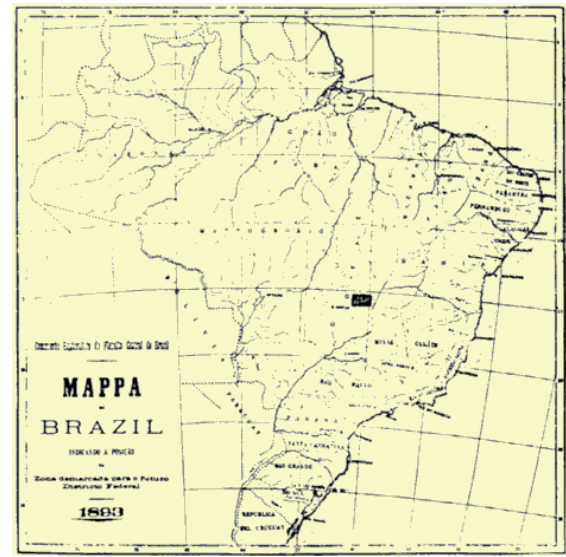

Fonte: Cavalcanti (2014)
Apesar de todos estes estudos, o projeto de transferência da capital para o interior do país, retornaria eventualmente ao Congresso, sem continuidade, ressurgindo somente em 7 de setembro de 1922, na comemoração do centenário da independência do Brasil, quando uma pedra fundamental foi colocada no local da futura capital, a nove quilômetros da cidade de Planaltina, no interior do então denominado "Quadrilátero de Cruls".

Em 1934, a Assembleia Nacional promulga uma nova constituição, cujo artigo $4^{\circ}$ das "Disposições Transitórias" estabelecia que: "Será transferida a Capital da União para um ponto central do Brasil” e que o Presidente da república "nomeará uma Comissão, que, sob instruções do Governo, procederá a estudos de várias localidades adequadas à instalação da nova capital" (BRASIL, 1934).

A Constituição de 1934 assim, manteve viva a ideia da transferência da capital, além de legitimar o mandato provisório de Vargas, que seria eleito como presidente da República, por voto indireto, pelo membros da própria Assembleia.

No entanto, uma nova Constituição foi promulgada em 1937 por Vargas (no período denominado de Estado Novo - 1937-1945), contudo, sem mencionar a futura capital do Brasil.

Em 5 de janeiro de 1953, porém, finalmente o Poder Executivo é autorizado a realizar os estudos definitivos para a escolha do local. Vargas cria então a Comissão de Localização da Nova Capital Federal (CLNCF), dirigida pelo General Aguinaldo Caiado de Castro, que encarregou a companhia brasileira de Aerofotogrametria, Cruzeiro do Sul, de fazer o levantamento aerofotogramétrico.

Os registros fotográficos originários deste levantamento se tornaram a base para os estudos realizados pela empresa americana Donald J. Belcher \& Associates que definiram possíveis locais para a futura capital.

Em 1954, os técnicos da empresa norte-americana visitam o quadrilátero demarcado pela Missão Cruls para estudar mais detalhadamente a geologia e a topografia da região onde, seria construída a nova capital, e definem cinco áreas (identificadas com códigos coloridos: 1 - castanho; 2 - verde; 3 - azul; 4 - vermelho, localizado na divisa Minas/Goiás; 5 - amarelo, era o mais distante da atual localização do Plano Piloto), para que fosse escolhida aquela que abrigaria Brasília (Figura 5). 
Figura 5 - Os sítios indicados pelo Relatório Belcher

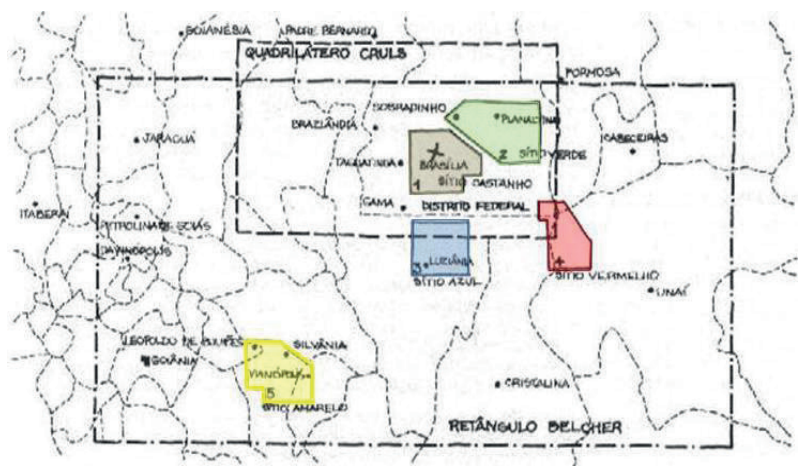

Fonte: Silhuetarquitetonica (2013).

Em 1955, o relatório Belcher foi submetido ao novo presidente da CLNCF, marechal José Pessoa Cavalcanti de Albuquerque, e entre os cinco locais, o 'castanho' foi finalmente escolhido no dia 15 de abril.

A área apresentava condições de clima temperado, terreno contínuo, boa drenagem e potencial para formação de lagos, pela possibilidade de represamento dos dois rios ali existentes: rio Paranoá e rio São Bartolomeu. Conforme indica o Relatório Belcher, a descrição do Sítio Castanho, o escolhido, superava de longe a descrição dos demais, sendo sua fisiografia inteiramente diferente da dos outros quatro. "A extensa planície, de suave declividade para os rios limítrofes, presta-se ao desenvolvimento de uma grande cidade de qualquer tipo possível, sem a obrigação de interromper acidentes topográficos" (BELCHER; DONALD J.; ASSOCIATES, 1956).

Ainda segundo o Relatório Belcher, o Sítio Castanho não é majestático apenas por sua topografia estufada e em suave declive, destacava-se também a riqueza em recursos hídricos. O sítio era demarcado por dois córregos, o Bananal e o Riacho Fundo, com a afluência do Vicente Pires, do Torto, do Vicente Pires, do Guará e dos demais fios de água que descem em direção a uma garganta borbulhante, a Cachoeira do Rio Paranoá (BELCHER; DONALD J.; ASSOCIATES, 1956).

Uma vez definido o local, o Governo do Presidente JK, realiza, em 1956, a transferência da Capital para o Planalto Central do Brasil. Dando efetividade a ideia de construção da Nova Capital, em 1956 é sancionada a Lei $n^{\circ}$ 2.874, que criou a Companhia Urbanizadora da Nova Capital (NOVACAP), com objetivo de tocar as obras da nova capital.

No início das obras um grande número de pessoas se transfere para Brasília para trabalhar na construção da Nova Capital. Os planos do governo e do próprio autor do Projeto para o Plano Piloto de Brasília eram que estas, no fim das obras, retornassem aos seus locais de origem, o que não ocorreu, de fato.

\section{0 processo de expansão urbana no DF}

Nos planos do urbanista Lúcio Costa, autor do projeto do Plano Piloto de Brasília, a cidade estava prevista para abrigar 500 a 700 mil habitantes. Apenas quando se aproximasse deste limite, seriam criadas na periferia as chamadas cidades satélites que seriam pequenas e complementares. Conforme Oliveira (2005), Lúcio Costa em entrevista cita: "para evitar aqueles fragmentos suburbanos que é sempre desagradável, desmoralizante... A cidade estava bem definida, depois surgiriam nessa periferia pequenas cidades, esse foi o esquema".

Mas a realidade instalada reverteu totalmente este planejamento. Brasília, apenas 50 anos após sua inauguração, já atinge a marca de 2.570.160 habitantes, segundo Censo 2010 (IBGE, 2014). E as cidades-satélites previstas apenas para após o adensamento de Brasília começaram a surgir antes mesmo de finalizadas as obras de construção da Nova Capital.

Desde os primeiros anos assim, a Nova Capital sofreu um forte incremento populacional em virtude do grande número de pessoas que para cá afluíram em busca de trabalho nas obras de construção da cidade e que, após a finalização destas, não quiseram retornar às suas cidades de origem.

Conforme Oliveira (2005, p. 5), Lúcio Costa cita que o engenheiro responsável pelas obras da capital, com a NOVACAP, Israel Pinheiro tinha considerado três possibilidades:

[...] uma vez terminada a fase inicial, dos 3 anos iniciais de trabalho intensivo, 1/3 da população obreira que tinha ido a Brasília para construir a cidade, chegado o momento da inauguração voltaria para o seu "país" de origem; o outro terço seria absorvido pelas próprias atividades locais urbanas; para o terceiro terço - como eram quase todos operários de tradição rural - a solução seria criar um cinturão verde, agrícola, em torno da cidade.

Mas isto não ocorreu porque os operários quiseram permanecer em Brasília e passaram a criar favelas próximas aos canteiros de obras no Plano Piloto. Para absorver este intenso fluxo migratório e erradicar as favelas (preservando assim, a área do Plano Piloto), a NOVACAP, antes mesmo que a cidade fosse inaugurada, foi escolhendo 
locais na periferia e criando assentamentos improvisados que vieram a se consolidar a partir da década de 60 como as chamadas "cidades-satélites" (mais tarde denominadas de Regiões Administrativas - RAs ${ }^{8}$ ) (Figura 6).

Figura 6 - Ocupação urbana em 1958

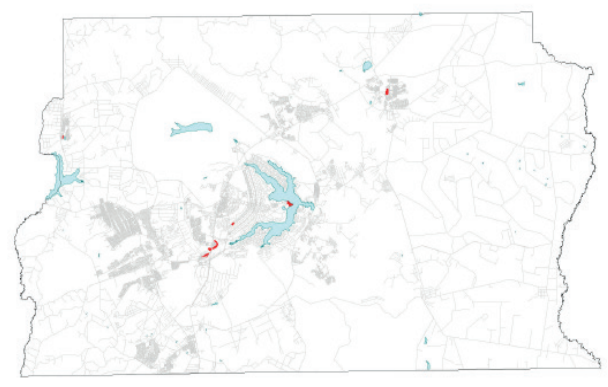

Fonte: GDF (1996, p. 29)

Seguindo as datas de fundação, foram criadas entre 1956 e 1969 as seguintes RAs: Gama (RA - II), Taguatinga (RA - III), Sobradinho (RA - V), Paranoá (RA - VII), Núcleo Bandeirante (RA - VIII), Ceilândia (RA - IX), Guará (RA - X), Cruzeiro (RA - XI) e Candangolândia (RA - XIX). Além destas, Brazlândia (RA - IV) e Planaltina (RA - VI), embora tenham sido também transformadas em Regiões Administrativas na década de 1960, são ainda mais antigas que as criadas entre 1956-1967, tendo sua fundação datada de 05/06/1933 e 19/08/1859, respectivamente (Tabela 2 ).

Tabela 2 - Distrito Federal - Cidades e Regiões Administrativas

Datas importantes

\begin{tabular}{|c|c|c|c|}
\hline \multicolumn{2}{|c|}{ Região Administrativa } & \multirow{2}{*}{$\begin{array}{l}\text { Fundação da Cidade } \\
\text { Data de Aniversário }\end{array}$} & \multirow{2}{*}{$\frac{\text { Criação da Região Administrativa }}{\text { Data }}$} \\
\hline RA & Nome & & \\
\hline 1 & Brasília & 21/04/1960 & 10/12/1964 \\
\hline$\|$ & Gama & $12 / 10 / 1960$ & 10/12/1964 \\
\hline III & Taguatinga & 05/06/1958 & 10/12/1964 \\
\hline IV & Brazlândia & 05/06/1933 & 10/12/1964 \\
\hline V & Sobradinho & $13 / 05 / 1960^{10}$ & 10/12/1964 \\
\hline $\mathrm{VI}$ & Planaltina & 19/08/1859 & 10/12/1964 \\
\hline VII & Paranoá & - & 10/12/1964 \\
\hline VIII & $\begin{array}{c}\text { Núcleo } \\
\text { Bandeirante }\end{array}$ & 19/12/1956 & 25/10/1989 \\
\hline IX & Ceilândia & 27/03/1971 & 25/10/1989 \\
\hline$x$ & Guará & 05/05/1969 & 25/10/1989 \\
\hline XI & Cruzeiro & $30 / 11 / 1959$ & $25 / 10 / 1989$ \\
\hline
\end{tabular}

Fonte: SUCAR/GERAR - novembro 1994 apud GDF (1996, p. 37).

8 Ao contrário dos demais Estados do Brasil que se encontram divididos em Municípios, o Distrito Federal, por ter sua municipalização vedada, conforme a Constituição Federal de 1988 (art. 32) divide-se territorialmente em Regiões Administrativas.
No período compreendido entre 1960 e 1970, apesar da taxa anual de crescimento do DF ter diminuído (passou de $120 \%$ para $14.39 \%$ ), o aumento populacional ainda foi bastante significativo (Figura 7). Segundo os dados demográficos da pesquisa Núcleo de Estudos Urbanos e Regionais/Instituto de Pesquisa Econômicas e Aplicadas (NEUR/IPEA) coletadas pela Codeplan/GDF a partir dos Censos do IBGE, a população do DF passou de 140 para 537 mil habitantes tendo o saldo migratório neste período sido de 30 mil pessoas/ano.

Figura 7 - Ocupação urbana em 1964

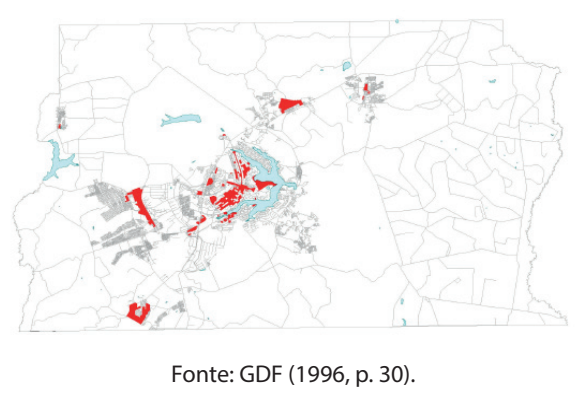

A partir da década de 70, parte significativa do fluxo migratório se direcionou para os municípios goianos limítrofes (Luziânia, Planaltina de Goiás, Padre Bernardo, Água Fria de Goiás, Valparaízo, Novo Gama, Cidade Ocidental, Águas Lindas e Santo Antônio do Descoberto), que iniciaram um processo de conurbação com as cidades-satélites do DF.

Isto contribuiu para que a cidade se configurasse atualmente no que a pesquisa NEUR/IPEA convencionou chamar de Aglomerado Urbano de Brasília que é formado pela junção da Brasília do Plano Piloto (que compreende o núcleo central onde a capital se localiza), da Brasília do DF (que compreende o Plano Piloto e as cidades satélites) e da Brasília composta pelo DF e alguns municípios do estado de Goiás (que foram geradas em grande parte pelo fluxo migratório intenso que se direcionou para a capital federal) (Figura 8).

9 "O povoado surgiu na década de 30 nas proximidades da Fazenda da família Braz, da qual o nome Brazlândia originou-se." Até o final de 1950 a cidade era apenas um pequeno vilarejo, com a construção da nova Capital, tudo se modificou. A cidade cresceu graças à chegada de migrantes de todo o Brasil e em especial do vizinho estado de Goiás (BRAZLÂNDIA, 2001).

10 "Planaltina é a mais antiga cidade do Distrito Federal [...]. A partir da primeira metade do século XVIII, inicia-se a exploração das minas de ouro e esmeralda e o povoamento do interior de Goiás pelos bandeirantes, desde então essa região passa a ser frequentada como ponto de passagem da estrada real, utilizada para o escoamento de ouro e arrecadação de dízimos territoriais. Nos termos do disposto no Artigo $2^{\circ}$ do Decreto ${ }^{\circ} 571$, de 19 de janeiro de 1967, a data oficial de fundação da cidade é 19 de agosto de 1859" (PLANALTINA, 2000). 
Figura 8 - O Aglomerado urbano de Brasília

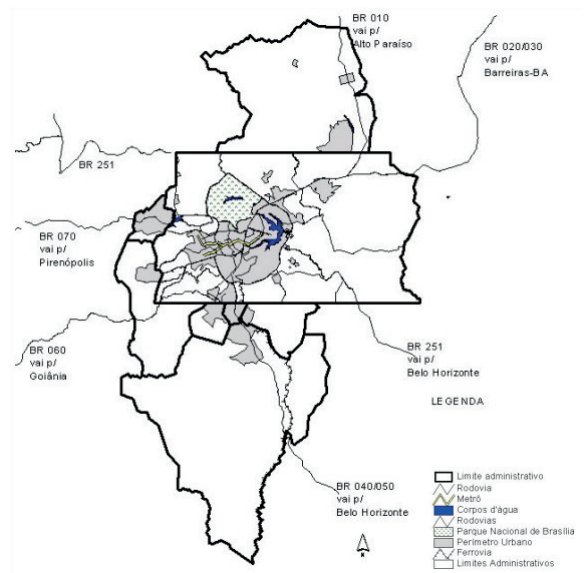

Fonte: GUIA (2010)

Entre 1970-1980 apesar da taxa de crescimento anual do DF continuar a cair (de $14.39 \%$ para $8.15 \%$ ), segundo o GDF (1996, p. 33), "essas taxas [ainda] eram muito elevadas, considerando-se que o volume da base populacional encontrava-se então bastante ampliado e o acréscimo da população, em termos absolutos, passava a ser significativo". De acordo com os dados da pesquisa NEUR/IPEA, no período compreendido entre 19701980, a população do DF atingiu o total de 1.177 mil habitantes e o saldo migratório foi de $44 \mathrm{mil}$ pessoas/ano. A participação migratória em 1970, representou 75\% da taxa de crescimento do Distrito Federal (GDF, 1996).

No decênio posterior porém, ocorrem modificações no total do saldo migratório. Apesar da população do DF continuar a crescer (chega a atingir $1.601 \mathrm{mil} \mathrm{ha-}$ bitantes), o fluxo migratório decresce gerando um saldo de 12 mil pessoas/ano (a exceção a esta tendência é feita à Periferia, cujo saldo migratório ao invés de decair, sobe de 6 mil pessoas/ano em 1970/1980, para 13 mil/ano entre 1980-1991).

Mas, no período compreendido entre 1991 a 1996, a tendência de queda também se modifica. $\mathrm{O}$ saldo migratório do Núcleo cresce para $20 \mathrm{mil}$ pessoas/ano (ao contrário do que ocorre nos demais aglomerados urbanos do Brasil que vêm seus núcleos perderem população), o da Periferia se eleva para $27 \mathrm{mil} /$ ano (atingindo $461 \mathrm{mil}$ habitantes) e a população do DF chega ao total de 1.817 mil habitantes.

Isto se justifica, pelo surgimento neste período de um maior número de invasões e implantação de uma política de distribuição de lotes (e conseqüente, criação de novas cidades satélites no território do DF) realizada pelo
Governo do Distrito Federal que levou a um aumento do fluxo migratório em direção ao DF. Segundo dados do GDF (1996), a participação migratória em 1991 correspondia a $33 \%$ da taxa de crescimento do DF.

Somente na década de 1990, graças à ação assistencialista do governo local, foram criadas dez novas cidades satélites: Samambaia (RA - XII), Santa Maria (RA - XIII), São Sebastião (RA - XIV), Recantos das Emas (RA - XV), Riacho Fundo I (RA - XVII), Riacho Fundo II (RA - XXI), Itapoá (RA - XXVIII), Sobradinho II (RA - XXVI), Varjão (RA - XXIII), Setor Complementar de Indústria e Abastecimento - SCIA (RA - XXV) (Figura 9 e Tabela 3).

Figura 9 - Ocupação urbana em 1991

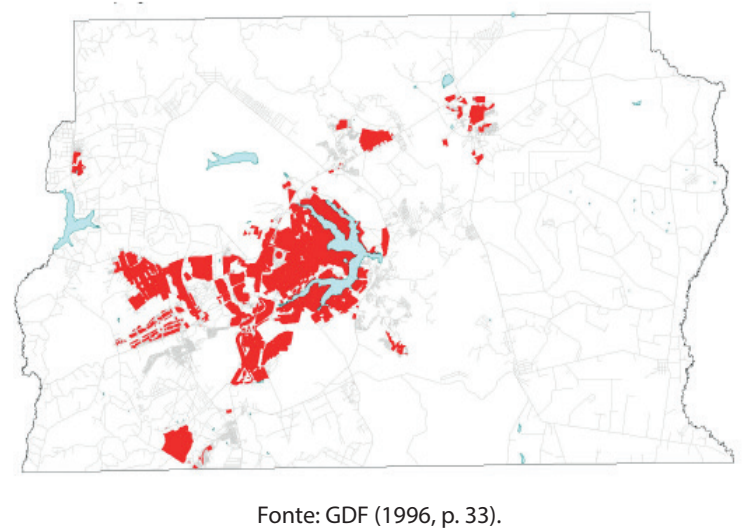

Tabela 3 - Distrito Federal - Cidades e Regiões Administrativas Datas importantes

\begin{tabular}{c|c|c|c}
\hline \multicolumn{2}{c|}{ Região Administrativa } & Fundação da Cidade & $\begin{array}{c}\text { Criação da Região } \\
\text { Administrativa }\end{array}$ \\
\hline RA & Nome & Data de Aniversário & Data \\
\hline XII & Samambaia & $25 / 10 / 1989$ & $25 / 10 / 1989$ \\
\hline XIII & Santa Maria & -- & $10 / 02 / 1993$ \\
\hline XIV & São Sebastião & -- & $25 / 06 / 1993$ \\
\hline XV & Recantos das Emas & -- & $28 / 07 / 1993$ \\
\hline XVI & Lago Sul & -- & $10 / 01 / 1994$ \\
\hline XVII & Riacho Fundo & -- & $15 / 12 / 1993$ \\
\hline XVIII & Lago Norte & -- & $10 / 01 / 1994$ \\
\hline XIX & Candangolândia & $03 / 11 / 1956$ & $27 / 01 / 1994$ \\
\hline \multicolumn{3}{c|}{ Fonte: SUCAR/GERAR - novembro 1994 apud GDF (1996, p. 37). }
\end{tabular}

Ainda na década de 1990, dois bairros antes integrantes do Plano Piloto, Lago Sul (RA - XVI) e Lago Norte (RA - XVIII), são alçados à condição de Região Administrativa (Tabela 3). E, em 2003, são transformadas em RAs: Águas Claras (RA - XX) que começou a ser construída na década de 1990; ParkWay (RA - XXIV) que era um bairro pertencente ao Núcleo Bandeirante; e Sudoeste/Octogonal (RA - XXII) que foi desmembrado da área da RA XI - Cruzeiro. 
Outro fator que contribuiu para o aumento populacional na década de 1990 foi a multiplicação dos loteamentos irregulares em área urbana e no DF. Conforme o GDF (1996), embora os primeiros tenham começado a surgir a partir de 1975, a quantidade destes só alcançou números exorbitantes entre 1985 e 1995, quando foram contabilizados 529 parcelamentos irregulares (chamados de "condomínios") em terras públicas griladas ou em terras particulares, contra os 150 loteamentos irregulares que existiam em 1985, configurando assim uma nova forma de organização do espaço habitacional.

Como mostra a Tabela 4, muitas das Regiões Administrativas criadas na década de 2000 foram fundadas ainda na década de 1990 tendo iniciado como invasões ou parcelamentos irregulares.

Tabela 4 - Distrito Federal - Cidades e Regiões Administrativas

Datas importantes

\begin{tabular}{|c|c|c|c|}
\hline \multicolumn{2}{|c|}{ Região Administrativa } & \multirow{2}{*}{$\begin{array}{c}\text { Fundação da Cidade } \\
\text { Lei de criação } \\
\text { dezembro de } 1992\end{array}$} & \multirow{2}{*}{$\begin{array}{c}\begin{array}{c}\text { Criação da Região } \\
\text { Administrativa }\end{array} \\
06 / 05 / 2003\end{array}$} \\
\hline$X X$ & Águas Claras & & \\
\hline XXI & Riacho Fundo II & $\begin{array}{c}\text { Criação do parcelamento } \\
1994\end{array}$ & 06/05/2003 \\
\hline$X X I I$ & $\begin{array}{l}\text { Sudoeste/ } \\
\text { Octogonal }\end{array}$ & $\begin{array}{l}\text { Projeto de Urbanismo } \\
\text { homologado em } 1989\end{array}$ & $06 / 05 / 2003$ \\
\hline XXIII & Varjão & $\begin{array}{l}\text { Primeiros loteamentos } \\
\text { irregulares déc. } 70-80\end{array}$ & 06/05/2003 \\
\hline XXIV & ParkWay & 13/03/1961 & $29 / 12 / 2003$ \\
\hline$X X V$ & SCIA & Início da invasão 1989 & $27 / 01 / 2004$ \\
\hline XXVI & Sobradinho II & 11/10/1991 & $27 / 01 / 2004$ \\
\hline XXVII & Jardim Botânico & Surgiu em 1999 & $31 / 08 / 2004$ \\
\hline XXVIII & Itapoã & $\begin{array}{l}\text { Final da década de 90, } \\
\text { início da invasão }\end{array}$ & 03/01/2005 \\
\hline XXIX & SAI & $21 / 04 / 1969$ & $14 / 07 / 2005$ \\
\hline$X X X$ & Vicente Pires & $\begin{array}{l}1997 \text { - início da divisão das } \\
\text { chácaras }\end{array}$ & 2008 \\
\hline XXXI & Fercal & 29/01/2012 & $29 / 01 / 2012$ \\
\hline
\end{tabular}

Fonte: Adaptado de SUCAR/GERAR - novembro 1994 apud GDF (1996, p. 37).

Compõem hoje o território do DF, 30 Regiões Administrativas (Figura 12) que passaram a compor, junto com o Plano Piloto, o território do DF e conferiram à cidade a forma polinucleada ${ }^{11}$ que ela hoje possui. Esse ter-

11 Segundo Paviani (1996, p. 224) “a organização do espaço urbano processou-se constantemente sob o formato de assentamentos esparsos, distantes entre si e do centro (o Plano Piloto de Brasília). Definimos Brasília como 'metrópole polinucleada', em razão do padrão reiterado de alocação de núcleos residenciais". ritório, mesmo no curto espaço de existência da Capital, já quase atingiu seu limite de adensamento. Restam agora áreas rurais, de preservação e impróprias para habitação devido ao relevo que passam a sofrer, cada vez mais, pressão para mudança de destinação.

Figura 10 - Regiões Administrativas do DF 2013

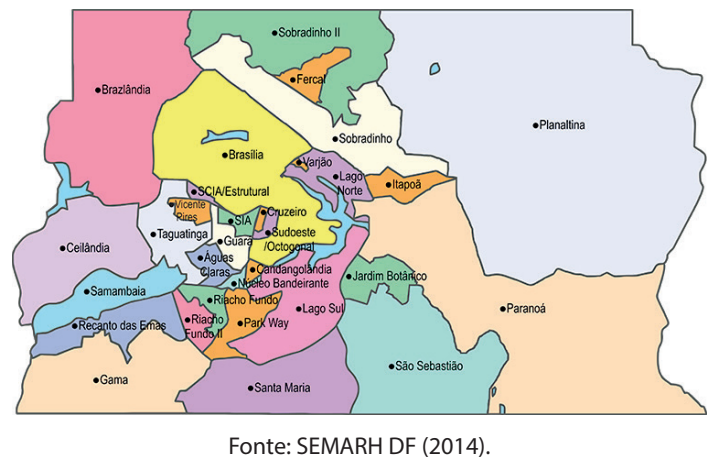

As tendências atuais de expansão urbana indicam que, enquanto entre 1990-1995, conforme Anjos (2012) os vetores de expansão urbana do território do DF se direcionavam para as RAs de Samambaia, Gama, Santa Maria, São Sebastião, Paranoá e Sobradinho (Figura 11), atualmente o fluxo se encontra direcionado para o sul do DF, Eixo Gama, Entorno Sul (Novo Gama, de Valparaíso e da Cidade Ocidental) e Luziânia (Figura 12), que veem sofrendo um forte processo de urbanização nas últimas décadas, configurando o que Anjos (2012) qualifica como o mais importante vetor de expansão da dinâmica territorial.

Figura 11- Vetores de expansão do DF. 1990-1995

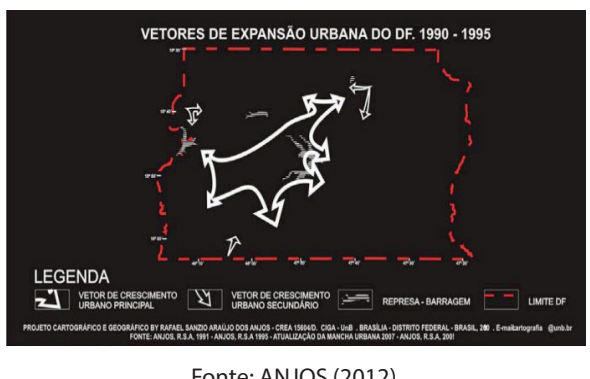

Fonte: ANJOS (2012).

Figura 12 - Vetores de expansão do DF. 2005-2010

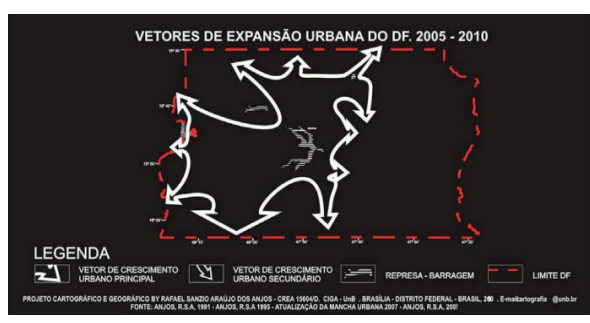

Fonte: ANJOS (2012). 
A atenção do Governo do DF para essa tendência de crescimento é relevante para o planejamento de estratégias e políticas para o ordenamento e garantia qualidade de vida da população residente na região.

Vê-se assim, que a história da organização espacial do DF foi marcada pela criação, muitas vezes sem planejamento urbanístico e em áreas distantes vários quilômetros do centro, o Plano Piloto, de núcleos urbanos visando suprir a demanda por habitação das diversas faixas de renda: baixa, média e, até alta (como foi o caso do Setor Noroeste).

Algumas dessas destas RAs, por sua vez, cresceram, inicialmente, desordenadas e mal equipadas passando a sofrer com a falta de infra-estrutura para garantir as necessidades básicas do cidadão, como o saneamento básico, abastecimento de água, assistência médica, transporte e, sobrecarregando assim, o Plano Piloto, onde estão concentrados a maior parte dos empregos, serviços de educação e saúde.

\section{Considerações finais}

Pode-se compreender com este estudo, que mesmo após algumas medidas preventivas que pudessem dar uma margem ao provável e possível crescimento desordenado urbano, não há, de fato, medidas totalmente eficazes para poder controlar este crescimento.

Não só no DF, mas em muitos outros estados e municípios brasileiros há este elevado índice de crescimento populacional inadequado, se levarmos em consideração o planejamento e as metas previstas e propostas para a urbanização das cidades.

Se faz assim necessário uso de ferramentas e recursos sociais, econômicos e culturais para lidar e passo a passo, melhorar os projetos de urbanização quanto a qualidade de vida e o desenvolvimento das nossas cidades e bairros.

\section{Referências}

ANJOS, Rafael Sanzio Araújo dos. Brasília: 50 anos de dinâmica territorial urbana. Revista Eletrônica: Tempo Técnica - Território, Brasília, v. 3, n. 1, 2012.

BARBEIRO, H.; CANTELE, B. R.; SCHNEEBERGER, C. A. História de olho no mundo do trabalho. São Paulo: Scipione, 2004.

BELCHER, Donald J. \& Associates. Relatório técnico sobre a nova capital da república. Rio de janeiro: Dasp, 1956.
BRASIL. Constituição (1891). Constituição da República Federativa do Brasil (de 24 de fevereiro de 1891). Disponível em: <http://www.planalto.gov.br/ccivil_03/constituicao/constituicao34.htm>. Acesso em: 01 maio 2014.

BRASIL. Constituição (1934). Constituição da República Federativa do Brasil (de 16 de julho de 1934). Disponível em: <http://www.planalto.gov.br/ccivil_03/constituicao/ constituicao34.htm>. Acesso em: 01 abr. 2014.

BRAZLÂNDIA. Brazlândia histórico. Disponível em: $<$ http://www.brazlandia.df.gov.br>. Acesso em: 01 jan. 2001.

BRITO, F.; SOUZA, J. Expansão urbana nas grandes metrópoles: o significado das migrações intrametropolitanas e da mobilidade pendular na reprodução da pobreza. Revista Perspectiva, São Paulo, v. 19, n. 4, p. 48-63, out./dez. 2005.

CAVALCANTI, Flavio R. Exploração e Estudos do Planalto Central. Comissão Cruls. Disponível em: <http://doc. brazilia.jor.br/Historia/Cruls.shtml>. Acesso em: 02 abr. 2014.

CASTELLS, Manuel. A questão urbana. 3. ed. São Paulo: Paz e Terra, 1983.

EL-DAHDAH, Farès. Brasília, um objetivo certa vez adiado. 10, abr. 2010. Disponível em: <http://www.vitruvius. com.br/revistas/read/arquitextos/10.119/3363>. Acesso em: 02 abr. 2014.

GOVERNO DO DISTRITO FEDERAL. Instituto de Planejamento Territorial e Urbano do Distrito Federal. Plano Diretor de Ordenamento Territorial e Urbano do Distrito Federal - PDOT: Documento de Referência: Perfil do Distrito Federal: Estudos Setoriais: Proposta do PDOT. Brasília: Codeplan, 1996.

GUIA, George Alex da; CIDADE, Lúcia Cony Faria. Segregação residencial e reprodução das desigualdades socioespaciais no aglomerado urbano de Brasília. Cad. Metrop., São Paulo, v. 12, n. 23, p. 145-168, jan./jun. 2010.

IBGE. Censo Demográfico, 2000. Disponível em: <http:// www.ibge.gov.br>. Acesso em: 22 jul. 2010.

IBGE. Censo Demográfico, 2014. Disponível em: <http:// www.ibge.gov.br>. Acesso em: 02 maio 2014.

IPEA; IBGE; UNICAMP. Caracterização e tendências da rede urbana do Brasil: estudos básicos para caracterização da rede urbana. IPEA, IBGE, UNICAMP. Brasília: IPEA, 2001.

MUMFORD, Lewis. A cultura das cidades. Belo Horizonte: Itatiaia, 1961. 
OLIVEIRA, Giovanna Ortiz de. Entrevista - Lucio Costa. 2005. Disponível em: <http://www.vitruvius.com.br/revistas $/ \mathrm{read} /$ entrevista $/ 06.023 / 3313$ ? page $=5>$. Acesso em: 04 fev. 2014.

PLANALTINA. Resumo histórico. Disponível em: <http:// www.df.gov.br/ravi>. Acesso em: 18 dez. 2000.

SILHUETARQUITETONICA. Há muito mais de 50 anos. 2010. Disponível em: <http://silhuetarquitetonica.wordpress.com/category/urbanismo-2/>. Acesso em: $08 \mathrm{dez}$. 2013.
SANTOS, Milton. A urbanização brasileira. 5. ed. São Paulo: Editora da Universidade de São Paulo, 2005.

SEMARH. Dados ambientais das Regiões Administrativa. Disponível em: <http://www.semarh.df.gov.br/qualiar/ mapa.html>. Acesso em: 09 abr. 2014.

UFRJ/IGEO/DEGEO. Grupo de Pesquisa RETIS. 2003. Disponível em: <http://www.igeo.ufrj.br/fronteiras/mapas/map002.htm>. Acesso em: 06 abr. 2014. 